\title{
Canadian Paediatric Neurology Workforce Survey and Consensus Statement
}

\author{
Asif Doja, Serena L. Orr, Hugh J. McMillan, Adam Kirton, Paula Brna, \\ Michael Esser, Richard Tang-Wai, Philippe Major, Chantal Poulin, \\ Narayan Prasad, Kathryn Selby, Shelly K. Weiss, E. Ann Yeh, David J.A. Callen
}

\begin{abstract}
Background: Little knowledge exists on the availability of academic and community paediatric neurology positions. This knowledge is crucial for making workforce decisions. Our study aimed to: 1) obtain information regarding the availability of positions for paediatric neurologists in academic centres; 2) survey paediatric neurology trainees regarding their perceptions of employment issues and career plans; 3) survey practicing community paediatric neurologists 4) convene a group of paediatric neurologists to develop consensus regarding how to address these workforce issues. Methods: Surveys addressing workforce issues regarding paediatric neurology in Canada were sent to: 1$)$ all paediatric neurology program directors in Canada $(n=9)$ who then solicited information from division heads and from paediatric neurologists in surrounding areas; 2) paediatric neurology trainees in Canada $(\mathrm{n}=57)$ and; 3$)$ community paediatric neurologists $(\mathrm{n}=27)$. A meeting was held with relevant stakeholders to develop a consensus on how to approach employment issues. Results: The response rate was $100 \%$ from program directors, $57.9 \%$ from residents and $44 \%$ from community paediatric neurologists. We found that the number of projected positions in academic paediatric neurology is fewer than the number of paediatric neurologists that are being trained over the next five to ten years, despite a clinical need for paediatric neurologists. Paediatric neurology residents are concerned about job availability and desire more career counselling. Conclusions: There is a current and projected clinical demand for paediatric neurologists despite a lack of academic positions. Training programs should focus on community neurology as a viable career option.
\end{abstract}

RÉSUMÉ: Enquête canadienne sur les effectifs en neurologie pédiatrique et déclaration de consensus. Contexte: Il existe peu de connaissances sur la disponibilité de postes universitaires et de postes en pratique dans la communauté en neurologie pédiatrique. Il est crucial de connaître la disponibilité de tels postes pour prendre des décisions au sujet des effectifs dans ce domaine. Les buts de notre étude étaient: 1) d'obtenir de l'information sur la disponibilité de postes en milieu universitaire en neurologie pédiatrique; 2) de connaître les perceptions des résidents en neurologie pédiatrique concernant les questions d'emploi et de plan de carrière; 3) de faire un tour d'horizon auprès des neurologues pédiatriques en pratique communautaire; 4) de convoquer des groupes de neurologues pédiatriques responsables de la formation dans ce domaine afin de développer un consensus concernant la façon de résoudre les problèmes de main d'œuvre. Méthode: Un questionnaire sur les problèmes de main d'œuvre en neurologie pédiatrique au Canada a été envoyé: 1) à tous les directeurs de programme de neurologie pédiatrique du Canada $(\mathrm{n}=9)$ qui ont alors demandé de l'information aux chefs de division et aux neurologues pédiatriques des environs ; 2) aux résidents en neurologie pédiatrique au Canada $(\mathrm{n}=57)$ et ; 3) aux neurologues pédiatriques en pratique dans la communauté $(\mathrm{n}=27)$. Nous avons tenu une réunion avec les individus concernés afin de développer un consensus sur la façon d'aborder les problèmes d'emploi. Résultats: Le taux de réponse des directeurs de programme a été de $100 \%$, de 57,9\% pour les résidents et de $44 \%$ pour les neurologues pédiatriques en pratique dans la communauté. Le nombre de postes universitaires projetés en neurologie pédiatrique est inférieur au nombre de neurologues pédiatriques qui sont ou seront en formation dans les cinq à dix prochaines années, malgré qu'il existe un besoin de neurologues pédiatriques en clinique. Les résidents en neurologie pédiatrique sont inquiets de la disponibilité de postes et désirent que l'orientation professionnelle soit améliorée. Conclusions: Il existe actuellement, ce qui sera également le cas dans le futur, une pénurie de neurologues pédiatriques malgré le manque de postes en milieu universitaire. Les programmes de formation devraient faire la promotion de la pratique de la neurologie dans la communauté comme étant un choix de carrière valable.

Keywords: education, neurology - pediatric

doi:10.1017/cjn.2015.360

Can J Neurol Sci. 2016; 43: 402-409

Paediatric Neurology training programs have grown substantially in Canada over the last decade. In 2001, there were three to four paediatric neurology training programs in Canada, each graduating one paediatric neurologist per year. ${ }^{1}$ However as of 2014 there were nine active paediatric neurology programs in Canada, each graduating at least one to two trainees per year. ${ }^{2}$ Training programs in Canada consist of either a five-year program of direct
From the University of Ottawa (AD, SLO, HJM), Ottawa; Western University (NP), London; University of Toronto (SKW, EAY), Toronto; McMaster University (DJAC), Hamilton, Ontario; University of Calgary (AK, ME), Calgary; University of Edmonton (RT), Edmonton, Alberta; University of Montreal (PM); McGill University (CP), Montreal, Quebec, Canada; Dalhousie University (PB), Halifax, Nova Scotia; University of British Columbia (KS), Vancouver, British Columbia, Canada.

Received February 2, 2015. Final Revisions Submitted September 24, 2015. Correspondence to: Asif Doja, Division of Neurology, Children's Hospital of Eastern Ontario, 401 Smyth Rd, Ottawa, Ontario, K1H 8L1. Email: adoja@ cheo.on.ca 
entry after medical school, or a three-year program undertaken after a minimum of three years of general paediatrics residency.

In 2012, a study by Piedboeuf et al., ${ }^{3}$ evaluating the numbers of trainees in all paediatric specialities across Canada, determined that the number of paediatric neurology trainees exceeded that any other paediatric subspecialty. The data suggested that the number of paediatric neurology trainees was greater than the projected need for future paediatric neurologists, with Canadian residents in paediatric neurology increasing from 30 in 2007 to 51 in 2011. However, this study had significant limitations. It focused strictly on estimating the number of future paediatric subspecialty positions in academic centres. The data was compiled by asking chairs of paediatrics departments across Canada to estimate the number of academic positions they envisioned being able to provide for various subspecialties over the next five years. They then compared this to the number of trainees enrolled in all paediatric subspecialty training programs. The survey did not factor in important variables such as differences in fellowship structure, job profile (clinical-research-education split), nor were questions directed at availability of community positions. The survey also did not examine the clinical demand for subspecialties such as paediatric neurology. Therefore, the possible surplus of paediatric neurologists suggested by the report requires careful consideration and additional data is required to fully address the issue.

Workforce assessments are increasingly recognized as important endeavours across medical subspecialties in Canada. A recent assessment of neurology specialists ${ }^{4}$ identified important issues, including matching of numbers and subspecialists to population needs, job opportunities, and future challenges. This study suggested a major weakness of the current employment system for neurologists in Canada is the lack of mechanisms to monitor the supply and distribution of neurologists in Canada and assess current and future needs, which are required to ensure appropriate neurological services and allocation of residency positions. The study also touched on child neurology, suggesting several important issues including a perceived increased need for both clinical and research paediatric neurologists. However, a dedicated, formal evaluation of the child neurology workforce has not been completed for over ten years. ${ }^{1}$

Due to concern regarding a shortage of academic positions in paediatric neurology, combined with the lack of overall information regarding paediatric neurology workforce needs, our group attempted: 1) to survey paediatric neurologists to obtain specific information regarding the availability of positions for paediatric neurologists in academic centres and the community; 2) to survey paediatric neurology trainees regarding their career plans as well as their perceptions of workforce issues; and 3) to convene an expert panel of paediatric neurologists with an interest and stake in education to develop a consensus regarding how best to address workforce issues in child neurology in Canada.

\section{MethoDS}

\section{Survey 1: Paediatric Neurologist Survey}

A 19 part questionnaire was developed by a group of five Canadian paediatric neurology program directors with the goal of obtaining information regarding: 1) current numbers of paediatric neurologists and the scope of their practices, 2) expected growth within the next ten years, 3) clinical demand, 4) current numbers of trainees and their expected disposition (see Appendix 1 for final version of questionnaire). The survey was administered electronically through the website SurveyMonkey®. It was sent to all paediatric neurology program directors across Canada $(n=9)$ with instructions to meet with their divisions before responding in order to be able to accurately address each question. The initial survey was sent in October 2013, with reminders sent in December 2013 and January 2014. Program directors were also assigned specific areas of the country for which they were asked to collect information from community neurologists and from academic centres with paediatric neurology consultants, but no residency programs. Numbers of paediatric neurologists in Canada were estimated by combining numbers from this survey as well as from Survey 3 (see below).

Survey responses were compiled and analyzed in Microsoft Excel. For survey questions 2, 5, 6, and 8, (see Survey 1, Appendix 1) mean values were calculated. For questions where rank orders were submitted (questions 3 and 14), weighted ranking was used to calculate the final results. Population statistics used to derive the number of patients serviced by each paediatric neurology centre were taken from the 2011 Canadian Census. ${ }^{5}$

\section{Survey 2: Paediatric Neurology Trainee Survey}

All residents enrolled in paediatric neurology training programs across Canada $(\mathrm{N}=57$, as of June 2014) were sent an electronic survey exploring workforce issues within the Canadian paediatric neurology community. Program directors and administrators were contacted by a study investigator (SLO) and asked to distribute the survey to all residents within their respective programs. The survey was originally sent in February 2014, with a reminder sent in May 2014. The survey was designed by the study investigators with the purpose of obtaining data pertinent to perceived issues with paediatric neurology training and the future workforce in Canada (see Appendix 2 for questionnaire). The survey was administered electronically through the website SurveyMonkey®. Three main issues were explored through a series of 16 questions: 1) the degree of concern amongst residents regarding the perceived lack of academic positions in paediatric neurology, 2) how the perceived lack of academic positions may be impacting resident career decisions, 3) how the current residency curricula are addressing workforce issues in Canada. All survey questions had a multiple-choice format, seven using a 5-point Likert scale and four allowing further elaboration through comment boxes. Residents were assured of anonymity and informed that survey completion constituted implicit consent to participate including analysis of the data generated.

\section{Survey 3: Community-Based Paediatric Neurology Physician Workforce Survey}

A separate survey was sent to practicing community paediatric neurologists across Canada. These individuals were identified by program directors as child neurologists who consider communitybased paediatric neurology (CB-PN) as being a part of their clinical practice. Candidates were sent an anonymous electronic link inviting them to participate in a web-based survey using REDCap. One reminder email was sent one week later. The survey consisted of 25-questions assessing eight broad areas: 1) confirming that their practice includes a significant component of paediatric neurology; 2) prior residency training; 3) prior exposure to $\mathrm{CB}-\mathrm{PN}$ during residency; 4) current practice setting; 5) type and number of patients seen; 6) electrodiagnostic services provided; 7) practice set up and; 8) university affiliation. The survey was sent to 27 physicians working in: British Columbia ( $\mathrm{N}=1)$; Alberta (5); Ontario (19) and 
New Brunswick (2). There were no physicians identified as CB-PNs in Saskatchewan, Manitoba, Québec, Nova Scotia, Newfoundland or Prince Edward Island.

\section{Consensus Development}

A Canadian paediatric neurology workforce group was established in April 2014 to develop a consensus regarding workforce issues. The workforce group consisted of all current and multiple past program directors in child neurology from across Canada, the president of the Canadian Association of Child Neurologists $(\mathrm{CACN})(\mathrm{NP})$ and the elected $\mathrm{CACN}$ resident representative (SLO), and a neutral chair with experience in residency training and consensus development (AK).

The workforce group convened a consensus conference as a satellite meeting to the $49^{\text {th }}$ Annual Canadian Congress of Neurological Sciences on June 3, 2014 in Banff, Alberta. All relevant data was summarized and presented by assigned delegates including the results of the workforce survey, ${ }^{3}$ a qualitative study on the perception of workforce issues in child neurology (cross reference qualitative study), the resident surveys as well as the 2012 Canadian Neurological Society Survey (as provided by the project leads). Descriptive data from an ad-hoc survey of Canadian child neurology graduates in the last ten years now working in the United States was also reviewed. The need for a community-based child neurologist survey was identified within the consensus meeting, with the resulting data reviewed by the working group at a later date, as summarized in the results.

The data from these surveys and discussions was used to generate a consensus statement, comprising a list of current problems with the workforce, issues to be addressed and a list of action items. The method of achieving consensus was modified from a simple majority vote to a more pragmatic and valid consensus process: all attending members (neutral chair excluded) could vote yes, no, or partial acceptance. Two-thirds non-objection was deemed significant consensus with all dissenting opinions noted.

\section{Results}

\section{Survey 1: Paediatric Neurologist Survey}

There was a $100 \%$ response rate $(n=9)$ from paediatric neurology centres across the country. There are currently 127 full

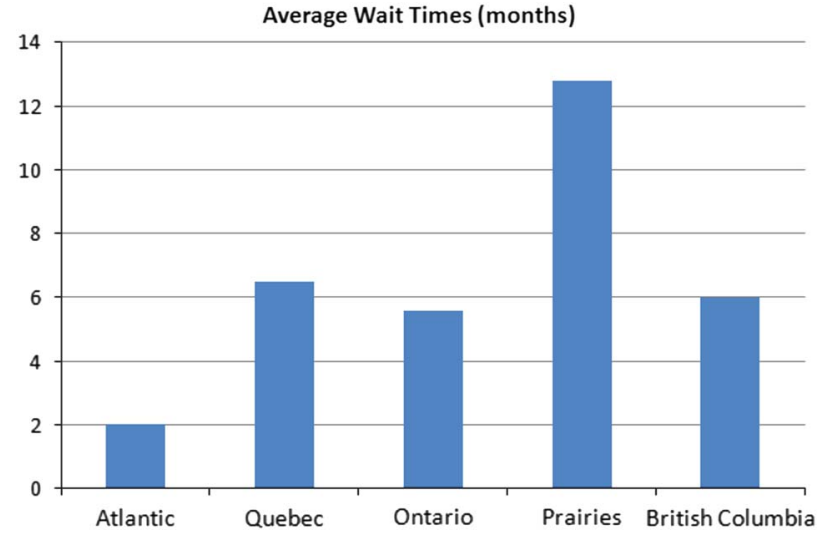

Figure 1: Summary of estimated average wait times for routine neurological consultation by Canadian geographic region.

time and eight part time paediatric neurologists practicing across Canada. After accounting for academic (education and research) and administrative responsibilities, this is equivalent to 89.2 full time clinical paediatric neurologists (i.e. 1.0 FTE clinical: seeing patients $100 \%$ of the time). Based on this, we estimate that each paediatric neurologist in Canada provides service for 375,299 people (approximately 87,794 children age 18 and under or 1.14 child neurologists for every 100,000 children). The regions with the greatest disparity between clinical neurologists and population demand are: British Columbia, the Maritimes and Québec (see Table 1). The average wait time to see a paediatric neurologist is 7.6 months (ranging from three months to two years) (Figure 1).

According to the polled paediatric neurology programs, an additional 131 paediatric neurologists would be ideal for providing appropriate service to the Canadian population. This was a subjective estimate, based on what would be perceived to be an "ideal" number for clinical care, teaching, research and administrative responsibilities. The average suggested proportion of academic to community paediatric neurologists was $70 \%$ academic and $30 \%$ community. According to the paediatric neurology program directors, general paediatricians in the academic centres across Canada have indicated a need for easier access to the following paediatric subspecialties in rank order of priority: neurology, developmental

Table 1: A summary of the number of pPaediatric Neurologists neurologists practicing across Canada and the associated regional population statistics.

\begin{tabular}{|c|c|c|c|c|c|}
\hline Region & Population & $\begin{array}{c}\text { Current Paediatric } \\
\text { Neurologists (Part-Time in } \\
\text { Brackets) }\end{array}$ & $\begin{array}{l}\text { Population Serviced } \\
\text { Per Neurologist* }\end{array}$ & $\begin{array}{l}\text { Clinical Full } \\
\text { Time } \\
\text { Equivalents }\end{array}$ & $\begin{array}{l}\text { Population Serviced } \\
\text { Per Clinical FTE }\end{array}$ \\
\hline $\begin{array}{l}\text { Maritimes (Newfoundland and Labrador, Nova Scotia, } \\
\text { New Brunswick and Prince Edward Island) }\end{array}$ & $2,32,7638$ & 9 & 258,626 & 5.6 & 415,649 \\
\hline Québec & $7,903,001$ & $20(3)$ & 367,581 & 19 & 415,947 \\
\hline Ontario & $12,851,821$ & $57(2)$ & 221,583 & 37 & 347,346 \\
\hline Manitoba & $1,208,268$ & 5 & 241,653 & 3.1 & 389,764 \\
\hline Saskatchewan & $1,033,381$ & 3 & & 3 & 344,460 \\
\hline Alberta & $3,645,257$ & $24(1)$ & 148,786 & 13.5 & 270,019 \\
\hline British Columbia & $4,400,057$ & $9(2)$ & 440,005 & 8 & 550,007 \\
\hline
\end{tabular}

*Part time neurologists are counted as 0.5

NB: Yukon, Northwest Territories and Nunavut have no paediatric neurologists and thus are not included in the table 


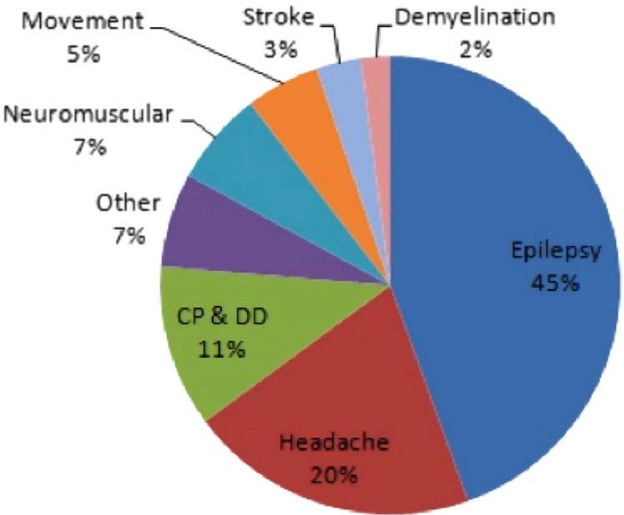

Figure 2: Summary of neurological diseases seen by Canadian paediatric neurologists practicing at academic centres.

paediatrics, gastroenterology and cardiology. The estimated proportions of specific disease categories seen by paediatric neurologists are summarized in Figure 2.

It is predicted that academic centres across Canada will be able to offer approximately three new academic paediatric neurology positions per year over the next ten years. The top five areas of expertise that are currently most desirable at academic institutions are: epilepsy, neonatal neurology, general neurology, neuromuscular neurology, and stroke.

It is possible for new graduates to practice as community paediatric neurologists in all provinces and territories. At present, there are 57 paediatric neurologists in training, with an estimate of 11 new paediatric neurologists graduating into practice each year. According to the program directors, four residents plan on working part-time upon completion of training.

The response rate for the resident survey was $57.9 \%(33 / 57)$. Several survey items had incomplete response rates, with a minimum of 29 respondents for each individual question.

Table 2 provides information on survey responses. Overall, $78.2 \%$ of the respondents indicated that they were either very concerned or concerned about the perceived lack of academic paediatric neurology positions in Canada. Although none of the respondents was currently in the process of transferring to another residency program, the majority of respondents had considered transfer $(53.1 \%)$. Respondents had a wide variety of plans for further postgraduate training after residency, with the most common plan being a clinical fellowship (40.6\%). The most common subspecialties that respondents were planning on pursuing were epilepsy $(31.3 \%)$, developmental medicine $(18.8 \%)$ and general neurology (18.8\%). Academic practice $(53.1 \%)$ and community practice with part-time academic hospital privileges $(40.6 \%)$ were more often selected as the desired future practice setting as compared to community practice alone $(9.4 \%)$. The majority of the respondents $(55.2 \%)$ indicated that they would like to apply for a primarily clinical position, as opposed to positions with more protected time for research.

There was a unanimous desire to remain in Canada for practice (100\%), with a few respondents also indicating that they would consider practice in the USA $(9.7 \%)$ or abroad $(9.7 \%)$. A significant proportion of respondents claimed that they would strongly consider or consider moving outside of Canada for a position $(42 \%)$, while the remainder were neutral or unsure $(16.1 \%)$ or would not consider moving for employment $(41.9 \%)$.
Table 2: Paediatric neurology resident perceptions regarding job prospects in Canada.

\begin{tabular}{|c|c|}
\hline Question & $\begin{array}{c}\text { Number of respondents } \\
\text { (percentage of respondents) }\end{array}$ \\
\hline \multicolumn{2}{|l|}{ 1. Concern regarding employment prospects } \\
\hline$\circ$ Very concerned & $14(43.8)$ \\
\hline ○ Concerned & $11(34.4)$ \\
\hline$\circ \quad$ Neutral & $5(15.6)$ \\
\hline$\circ \quad$ Not very concerned & $2(6.2)$ \\
\hline$\circ \quad$ Not concerned & $0(0)$ \\
\hline$\circ$ Total number of respondents & $32(97)$ \\
\hline \multicolumn{2}{|l|}{ 2. Consideration of transfer to another program } \\
\hline$\circ$ In the process of transferring & $0(0)$ \\
\hline$\circ$ Have strongly considered transfer & $6(18.7)$ \\
\hline$\circ$ Have considered transfer & $11(34.4)$ \\
\hline$\circ$ Have not considered transfer & $15(46.9)$ \\
\hline$\circ$ Total number of respondents & $32(97)$ \\
\hline \multicolumn{2}{|l|}{ 3. Future plans for training* } \\
\hline$\circ \quad$ No further training & $5(15.6)$ \\
\hline$\circ \quad$ Clinical fellowship & $13(40.6)$ \\
\hline$\circ$ Research fellowship & $5(15.6)$ \\
\hline - Master's of /PhD & $1(3.1)$ \\
\hline - Both a fellowship and Master's/PhD & $4(12.5)$ \\
\hline$\circ$ Unsure & $7(21.9)$ \\
\hline$\circ$ Total number of respondents & $32(97)$ \\
\hline \multicolumn{2}{|l|}{ 4. Desired subspecialty* } \\
\hline - Epilepsy & $10(31.3)$ \\
\hline$\circ \quad$ Undecided & $7(21.9)$ \\
\hline - Developmental & $6(18.8)$ \\
\hline ○ General Neurology & $6(18.8)$ \\
\hline ○ Demyelinating & $2(6.3)$ \\
\hline - Headache & $2(6.3)$ \\
\hline$\circ \quad$ Neurogenetics & $2(6.3)$ \\
\hline$\circ \quad$ Neonatal Neurology & $2(6.3)$ \\
\hline$\circ$ Stroke & $1(3.1)$ \\
\hline$\circ \quad$ Neurometabolics & $1(3.1)$ \\
\hline$\circ$ Total number of respondents & $32(97)$ \\
\hline \multicolumn{2}{|l|}{ 5. $\quad$ Future career plans for practice setting* } \\
\hline$\circ$ Community & $3(9.4)$ \\
\hline $\begin{array}{l}\text { Community with part-time academic } \\
\text { privileges }\end{array}$ & $13(40.6)$ \\
\hline - Academic hospital & $17(53.1)$ \\
\hline ○ Unsure & $3(9.4)$ \\
\hline$\circ$ Total number of respondents & $32(97)$ \\
\hline \multicolumn{2}{|c|}{ 6. Type of desired position if planned academic practice* } \\
\hline ○ Primarily clinical & $16(55.2)$ \\
\hline o Mixed clinical/research & $7(24.1)$ \\
\hline$\circ$ Primarily research & $1(3.5)$ \\
\hline$\circ$ Unsure & $8(27.6)$ \\
\hline$\circ$ Total number of respondents & $29(87.9)$ \\
\hline
\end{tabular}


Table 2. Continued

\begin{tabular}{|c|c|}
\hline Question & $\begin{array}{l}\text { Number of respondents } \\
\text { (percentage of respondents) }\end{array}$ \\
\hline \multicolumn{2}{|l|}{ 7. Plans for practice location* } \\
\hline - Canada & $31(100)$ \\
\hline$\circ \quad$ United States & $3(9.7)$ \\
\hline - Outside of North America & $3(9.7)$ \\
\hline$\circ$ Total number of respondents & $31(93.9)$ \\
\hline \multicolumn{2}{|c|}{ 8. Degree of consideration for moving outside of Canada for position } \\
\hline - Strongly consider & $7(22.6)$ \\
\hline - Somewhat consider & $6(19.4)$ \\
\hline - Neutral/unsure & $5(16.1)$ \\
\hline - Not really consider & $8(25.8)$ \\
\hline - Not consider at all & $5(16.1)$ \\
\hline - Total number of Tab respondents & $31(93.9)$ \\
\hline \multicolumn{2}{|c|}{ 9. Degree of attachment to particular location in Canada* } \\
\hline - Strongly attached/would not consider moving & $5(16.1)$ \\
\hline ○ Strongly attached/would consider moving & $16(51.6)$ \\
\hline - Somewhat attached & $6(19.4)$ \\
\hline$\circ \quad$ Not attached & $5(16.1)$ \\
\hline ○ Unsure & $0(0)$ \\
\hline - Total number of respondents & $31(93.9)$ \\
\hline \multicolumn{2}{|c|}{$\begin{array}{l}\text { 10. Recommendation of Paediatric Neurology as career to } \\
\text { medical student }\end{array}$} \\
\hline ○ Strongly recommend & $1(3.2)$ \\
\hline - Recommend & $20(64.5)$ \\
\hline$\circ \quad$ Neutral & $8(25.8)$ \\
\hline ○ Recommend against & $2(6.5)$ \\
\hline - Strongly recommend against & $0(0)$ \\
\hline - Total number of respondents & $31(93.9)$ \\
\hline \multicolumn{2}{|c|}{ 11. Impact of lack of positions on career counseling for medical students } \\
\hline ○ Strongly impact & $6(19.4)$ \\
\hline$\circ$ Somewhat impact & $15(48.4)$ \\
\hline$\circ$ Neutral & $5(16.1)$ \\
\hline$\circ$ Not really impact & $5(16.1)$ \\
\hline - Not impact at all & $0(0)$ \\
\hline - Total number of respondents & $31(93.9)$ \\
\hline \multicolumn{2}{|c|}{ 12. Satisfaction with how their centre is addressing lack of positions* } \\
\hline$\circ$ Very satisfied & $1(3.2)$ \\
\hline - Somewhat satisfied & $9(29)$ \\
\hline ○ Neutral & $11(35.5)$ \\
\hline ○ Not very satisfied & $10(32.3)$ \\
\hline$\circ \quad$ Not satisfied at all & $0(0)$ \\
\hline$\circ$ Total number of respondents & $31(93.9)$ \\
\hline \multicolumn{2}{|c|}{ 13. Opinion about the number of residents being trained at their centre } \\
\hline$\circ$ Too many & $7(22.6)$ \\
\hline$\circ$ Just right & $20(64.5)$ \\
\hline$\circ$ Not enough & $4(12.9)$ \\
\hline ○ Total number of respondents & $31(93.9)$ \\
\hline
\end{tabular}

Table 2. Continued

\begin{tabular}{ll|c}
\hline Question & $\begin{array}{c}\text { Number of respondents } \\
\text { percentage of respondents) }\end{array}$ \\
\hline $14 . \quad$ Agreement with statement about centre training residents for service \\
\hline$\circ \quad$ Strongly agree & $3(9.7)$ \\
\hline$\circ \quad$ Agree & $10(32.3)$ \\
\hline$\circ \quad$ Neutral & $6(19.4)$ \\
\hline$\circ \quad$ Disagree & $10(32.3)$ \\
\hline$\circ \quad$ Strongly disagree & $2(6.5)$ \\
\hline$\circ \quad$ Total number of respondents & $31(93.9)$ \\
\hline $15 . \quad$ Number of residents they believe their centre should train every year \\
\hline$\circ \quad$ Should no longer admit residents & $0(0)$ \\
\hline$\circ \quad$ Should admit less than one/year & $6(19.4)$ \\
\hline$\circ \quad$ Should admit one/year & $15(48.4)$ \\
\hline$\circ \quad$ Should admit two/year & $6(19.4)$ \\
\hline$\circ \quad$ Should admit three/year & $2(6.5)$ \\
\hline$\circ \quad$ Other & $2(6.5)$ \\
\hline$\circ \quad$ Total number of respondents & $31(93.9)$ \\
\hline 16. & Opinion about the need to change the residency curriculum \\
\hline$\circ \quad$ No & $7(23.3)$ \\
\hline$\circ \quad$ Yes & $23(76.7)$ \\
\hline$\circ \quad$ Total number of respondents & $30(90.9)$ \\
\hline
\end{tabular}

*Multiple responses given by some respondents

Most respondents indicated that they were strongly attached to one particular location within Canada but that they would consider moving within Canada for work (51.6\%).

When asked if they would recommend paediatric neurology as a career to medical students, respondents most commonly stated that they would recommend it $(64.5 \%)$, with only $3.2 \%$ claiming that they would strongly recommend it and just under one third who would either be neutral $(25.8 \%)$ or recommend against it (6.5\%). The perceived lack of academic positions in Canada would impact or strongly impact the majority of respondents $(67.8 \%)$ in how they would counsel a medical student about selecting a career in paediatric neurology.

Respondents were divided regarding their degree of satisfaction with how their training centre is addressing the perceived lack of academic positions. Almost two thirds $(64.5 \%)$ indicated that they believe that their centre is training the appropriate number of residents, as opposed to too many $(22.6 \%)$ or too few $(12.9 \%)$. Forty-two percent either agreed or strongly agreed with a statement declaring that their centre was training residents with service priorities being considered above educational priorities, whereas the remainder were either neutral $(19.4 \%)$ or disagreed to varying degree $(38.8 \%)$. The most commonly selected response to the question regarding the appropriate number of residents to train was one resident per centre per year $(48.4 \%)$. Finally, the vast majority of respondents $(76.7 \%)$ believe that the curricula of paediatric neurology training programs need to change in order to reflect the perceived lack of academic positions in Canada. Most respondents who provided comments for this question highlighted the need for more career counselling and more teaching around community neurology as well as practice management. 


\section{Table 3: Community-Based Paediatric Neurology Work Force Survey}

\begin{tabular}{|c|c|c|}
\hline 1. & Eligibility to participate: & \\
\hline & Does your practice include paediatric neurology? & Yes: $12 / 12(100 \%)$; No: $0 \%$ \\
\hline \multirow[t]{7}{*}{2.} & Prior residency and/or fellowship training: & \\
\hline & List all FULL residency program(s) completed & Paediatric Neurology: 10/12 (83\%) \\
\hline & & Paediatrics: 7/12 (58\%) \\
\hline & & Adult Neurology: $2 / 12(17 \%)^{*}$ \\
\hline & Did you complete residency training in Canada? & Yes: $11 / 12(92 \%)$; No: $1 / 12(8 \%)$ \\
\hline & Did you complete subspecialty fellowship? & Yes: $3 / 12(25 \%)$; No: $9 / 12(8 \%)$ \\
\hline & Year you began practicing paediatric neurology in Canada? & Median $=1992($ range 1982 to 2014$)$ \\
\hline \multirow[t]{2}{*}{3.} & Exposure to community-based paediatric neurology (CB-PN) & \\
\hline & Were you exposed to CB-PN during residency? & Yes: $2 / 12(17 \%)$; No: $10 / 12(83 \%)$ \\
\hline \multirow[t]{7}{*}{4.} & Current practice setting: & \\
\hline & Do you hold active hospital privileges? & Yes: 9/12 (75\%); No: 3/12 (25\%) \\
\hline & Where do you currently see patients? & Private office/clinic: $9 / 12(75 \%)$ \\
\hline & & Hospital ambulatory clinic 6/12 (50\%) \\
\hline & & Hospital inpatients: $9 / 12(75 \%)$ \\
\hline & & Emergency room: $7 / 12(58 \%)^{*}$ \\
\hline & Do you provide over-night, on-call services? & Yes: 5/11 (45\%); No: 6/11 (55\%) \\
\hline \multirow[t]{8}{*}{5.} & Patients seen: & \\
\hline & Estimate $\%$ time spend in following areas: & Paediatric Neurology: Mean 77\% (range 30-100\%) \\
\hline & & Paediatrics: Mean 14\% (range 0-100\%) \\
\hline & & Adult Neurology: Mean $13 \%$ (range $0-70 \%$ ) \\
\hline & Estimate the \# of days worked each week? & Mean $=4.5$ days (range 3 to 5 days) \\
\hline & Estimate the \# of CLINIC days each week? & Mean $=3.5$ days (range 1 to 5 days) \\
\hline & Estimate the \# new consults seen each week? & Mean $=16$ patients (range 4 to 40 ) \\
\hline & Estimate your wait time for non-urgent consults? & Mean $=14$ weeks (range 5 to 36 weeks) \\
\hline \multirow[t]{3}{*}{6.} & Electrophysiological services provided: & \\
\hline & Specify any electrodiagnostic testing you offer? & EEG: 7/12 (58\%); EMG 0/12 \\
\hline & & EPs: 0/12; Sleep study $1 / 12(8 \%)$ \\
\hline \multirow[t]{6}{*}{7.} & Practice set-up & \\
\hline & Do you feel physicians could bill sufficient amount from paediatric neurology alone? & Yes: 9/11 (82\%); No: 2/11 (18\%) \\
\hline & Are you incorporated? & Yes: $12 / 12(100 \%)$; No: $0 \%$ \\
\hline & Do you have a solo or group practice? & Solo: 8/12 (67\%); Group 4/12 (33\%) \\
\hline & For group practices, do you share: & Office space $4 / 4$ (100\%); Nurse $4 / 4(100 \%)$ \\
\hline & & Receptionist 4/4 (100\%); Technologist 1/4 (25\%) \\
\hline \multirow[t]{3}{*}{8.} & University affiliation? & \\
\hline & Do you currently have a university affiliation? & Yes: $10 / 12(80 \%) ;$ No 0/12; No reply $2 / 12(20 \%)$ \\
\hline & Are you interested in developing a relationship with university and/or supervising residents? & Yes: $9 / 12(75 \%)$; No $1 / 12(8 \%)$; No reply $2 / 12$ \\
\hline
\end{tabular}

$\#=$ number; $\mathrm{EEG}=$ electroencephalography $\mathrm{EMG}=$ electromyelography; $\mathrm{EPs}=$ evoked potentials

*Note: totals $\%$ does not add up to $100 \%$ as Respondents were permitted to choose $>1$ more than one answer.

\section{Survey 3: Community-Based Paediatric Neurology Physician Workforce Survey}

Response rate of the community-based paediatric neurology physician workforce survey was 12/25 (48\%). Based upon their stated academic affiliation, respondents appeared to be from BC (1), Alberta (1) and Ontario (8). Two respondents did not list academic affiliations.
All respondents confirmed that they include paediatric neurology as part or all of their current clinical practice (Table 3). Respondents indicated that they completed full residency programs in one or more of: paediatric neurology (83\%), paediatrics $(59 \%)$ or adult neurology $(17 \%)$. Three respondents indicated that they had pursued subspecialty fellowship training after residency completion, all in epilepsy/electroencephalography (EEG). 
Only $2 / 12(17 \%)$ respondents indicated that they had some exposure to community-based paediatric neurology during their residency training. One indicated that they had a mandatory clinic rotation in community-based paediatric neurology and an elective opportunity during their residency. One commented that they felt fortunate during their residency training to have had staff supervisors who worked in the community and that this exposure encouraged them to consider this career option. Two respondents expressed sentiments that during their own residency training they were unaware that a paediatric neurologist could practice in the community in an office-based setting without immediate access to magnetic resonance imaging with sedation and/or EEG.

Practice setting varied among respondents (Table 2). Although $75 \%$ indicated that they did see patients in a private office or clinic, many also worked in hospital ambulatory clinics (50\%), hospital inpatient wards (75\%) and/or emergency room consultations (58\%). About half of respondents (45\%) indicated that they offered over night on-call services in the community within which they worked.

Most respondents $(75 \%)$ indicated that at least $85 \%$ of their clinical workload was specifically paediatric neurology consultation or follow-up visits. Five (42\%) indicated that they see exclusively paediatric neurology patients. A smaller subset $(25 \%)$ indicated that they allocate only $30-50 \%$ of clinical time to paediatric neurology cases with the remaining 50-70\% devoted to either paediatric and/or adult neurology consultation services. Respondents reported working a mean of 4.5 days each week (range 3.0 to 6.0 days) with a mean of 3.5 days (range 1.0 to 5.0 days) allocated specifically to clinical work. Respondents estimated that their waiting time for a non-urgent consult was an average of 14 weeks (range 5 to 36 weeks). Over half (58\%) of community-based paediatric neurologists offered EEG services. One respondent performed sleep studies. No community based paediatric neurologists offered other electrodiagnostic services such as electromyography or evoked potentials.

The majority of respondents $(9 / 11 ; 82 \%)$ felt that it was possible for a physician to generate sufficient billings from paediatric neurology consults alone to remain self-sufficient. This is consistent with the observation that $42 \%$ of community based paediatric neurologists were seeing exclusively paediatric neurology consultations. It is important to note however, that physician billing codes and remuneration varies greatly from province-to-province and that this survey largely polled community-based paediatric neurologists from Ontario as well as Alberta and British Columbia. This may not be applicable to all provinces since there was a notable absence of community-based paediatric neurologists in heavily populated provinces such as Québec. The majority of community-based paediatric neurologists $(67 \%)$ indicated that they work in a solo or independent practice and all respondents were incorporated.

\section{Consensus statement}

Table 4 indicates the working group's consensus regarding the data presented. With regards to problems 1 and 2, the working group discussed the issue of how many training positions should be offered per year. The consensus of the working group was as follows:

i. There is no current indication to reduce the number of training positions. At present, programs should neither restrict nor increase their number of trainees.

ii. This issue will require continued surveillance. It was suggested that the training issues identified here be reviewed in two to three years including collection of updated data and reconvening of the working group.

The second issue discussed was regarding who should control the number of residents in any given program. The question arising pertained to whether it should it be regulated at the program level, the medical school level, the provincial level or the national level (i.e. by the CNSF or the Royal College of Physicians and Surgeons of Canada). The consensus of the working group was as follows:

iii. Decisions regarding resident numbers in any given program will ultimately be decided by each program, in conjunction with their medical school's postgraduate education office. It is hoped that each program will be actively involved with national initiatives such as this, with consideration of the issues outlined in this document when making such decisions.

Regarding problem 3, the working group noted that for many trainees, resident career goals often include more clinical, community-based practices. As such, increasing the proportion of community paediatric neurologists appeared to be a viable option to better match resident career goals with population needs. It was also acknowledged that knowledge and experience in community paediatric neurology practice amongst trainees and academic paediatric neurologists is poor and needs to be improved. The consensus of the working group was as follows:

iv. There should be greater emphasis in exposing trainees (both medical students and residents) to community paediatric neurology as a viable career option, including through electives, academic half-day and other educational sessions. v. Community paediatric neurology rotations should be strongly encouraged but not be mandatory.

vi. Community paediatric neurologists should be involved in post graduate training committees.

\section{Discussion AND Future Directions}

The survey data and working group consensus suggest that while academic paediatric neurology positions in Canada may be limited, a number of paediatric neurology consultants are needed for clinical patient care. The United States of America has a projected shortage of child neurologists as compared to other paediatric subspecialists, ${ }^{6}$ with 1.27 child neurologists for every 100,000 children. $^{7}$ This is similar to the ratio we estimated in Canada of approximately 1.14 per 100,000 children, However, matching the need for child neurologists with the likely need for

Table 4: Working Group consensus regarding survey data

1. The current graduation rate of Canadian paediatric neurologists exceeds projected Canadian academic paediatric neurology positions.

2. Clinical need for paediatric neurologists exceeds current supply.

3. Current training models do not adequately encompass community training to address points 1 and 2 . 
more community practitioners will require careful monitoring of trainee numbers and trainee career goals.

The working group proposes an increased emphasis on community neurology in training programs as an important method to address some of the employment issues identified. As per the data presented, successful practice as community-based paediatric neurologists is feasible in at least some Canadian provinces. Community-based paediatric neurologists may combine their paediatric neurology skills with paediatric and/or adult neurology consultations or offer epilepsy/EEG services as part of their practice. Our findings indicate that CB-PN themselves underscored the need for mentoring and/or modelling of what a community-based paediatric neurology practice may be like, in order to present this as a career possibility for residents who may only have exposure to academic centre-based paediatric neurology.

However, many questions regarding community neurology practice remain unanswered. What is the minimum size of a community that can support a community paediatric neurology practice? How does one ensure a community paediatric neurology practice is economically viable? Are we supporting our trainees adequately with regards to developing the skills to manage a community practice? The working group plans to address these questions in the near future.

The working group primarily focussed on community neurology as a viable path for paediatric neurology trainees. With regards to workforce issues, further research should focus on whether we in fact need more academic paediatric neurologists. However, to examine this issue, one needs to consider the roles academic neurologists serve apart from clinical care. Research, teaching and advocacy are all key parts of academic practice. As such, future studies should focus on whether these areas of academic practice need to be expanded in Canada - if so, this may provide evidence to advocate for an increased number of academic child neurology positions in the future.

Our results also can serve as the impetus for the discussion of other models of health care delivery for paediatric and adolescent neurological patients. For example, should we try to further incorporate telemedicine and outreach clinics to remote areas? Should we attempt to train advanced practice nurses to help administer neurological care in rural areas?

There are several limitations of our study. Due to logistical and resource reasons, we were unable to send out multiple reminders to participants to complete the various surveys. As such, our response rates were variable amongst the surveys, resulting in the potential omission of important viewpoints from key stakeholders. Even Survey 1, which had a $100 \%$ response from all program directors, was limited in that it required program directors to respond on behalf of division heads and paediatric neurologists in neighbouring areas. It would have been preferable to survey these individuals directly as opposed to having their responses gathered through the program directors. Survey 1 also makes estimates of physician need based on the number of FTE's; however, there may be different interpretations of what constitutes an FTE at different centres. With regards to surveying CB-PN's the names of those surveyed were obtained simply by asking all co-authors to contribute names of persons known to be practicing community based paediatric neurology; this method, however, has the potential to potentially miss some CB-PN's. As such, Table 1 should at best be interpreted as a rough estimation of paediatric neurologist numbers. Finally, there are other stakeholders who were not part of the consensus group whose input could potentially be relevant to workforce decisions in child neurology, including departmental/division chairs, representatives from the Royal College of Physicians and Surgeons of Canada, postgraduate deans, representatives from provincial health ministries and patients/caregivers.

As mentioned in the consensus summary, the working group suggests close monitoring of workforce data, including where recent paediatric neurology graduates have set up practice, over the next two to three years, with a plan to re-examine the consensus statements. Ideally, with this type of close monitoring, we, as paediatric neurologists in Canada, will be able to fulfil our duties with regards to patient care as well as our responsibility to train the next generation of Canadian paediatric neurologists.

\section{DisClOSURES}

Asif Doja, Serena Orr, Hugh McMillan, Adam Kirton, Paula Brna, Michael Esser, Richard Tang-Wai, E. Ann Yeh, Shelly Weiss, Chantal Poulin, and David Callen do not have anything to disclose.

Philippe Major has the following disclosures: Novartis Advisory Board and speaker, Research grant and speaker honoraria; Eisai, Advisory Board, Honoraria. A. Narayan Prasad has the following disclosure: Eisai, Contractual agreement, Honoraria; EMD Serono, Contractual agreement, Honoraria. Kathryn Selby has the following disclosures: DTC, Research/Clinical trial, Research support; GSK, Research/Clinical trial, Research support; Eli Lilly, Research/Clinical trial, Research support.

\section{SUPPLEMENTARY MATERIAL}

To view supplementary material for this article, please visit http://dx.doi./org/10.1017/cjn.2015.360.

\section{REFERENCES}

1. Keene DL, Humphreys P. Inventory of pediatric neurology "manpower" in Canada. Can J Neurol Sci [Internet]. 2005 Aug [cited 2014 Nov 4];32(3):306-10.

2. Doja A. Pediatric neurology training in Canada: current status and future directions. Can J Neurol Sci [Internet]. 2012 May [cited 2014 Nov 4];39(3):369-77.

3. Piedboeuf B, Jones S, Orrbine E, Filler G. Are the career choices of paediatric residents meeting the needs of academic centres in Canada? Paediatr Child Health [Internet]. 2012 Jan [cited 2014 Nov 4];17(1):17-20.

4. Kirby S, Weston LE, Barton JJS, et al. Report of the Canadian Neurological Society Manpower Survey. Can J Neurol Sci. Epub 2015 Nov 24.

5. Population and Dwelling Count Highlight Tables, 2011 Census [Internet].

6. Werner RM, Polsky D. Comparing the supply of pediatric subspecialists and child neurologists. J Pediatr [Internet]. Elsevier; 2005 Jan 1 [cited 2015 Jun 23];146(1):20-5.

7. Polsky D, Weiner J, Bale JF, Ashwal S, Painter MJ. Specialty care by child neurologists: a workforce analysis. Neurology [Internet]. 2005 Mar 22;64(6):942-8. 